\title{
C|plestatio
}

\section{Presença digital em portais de periódicos: proposta de análise}

\author{
Juliana Aparecida Gulka \\ Mestre; Universidade Federal de Santa Catarina, Florianópolis, SC, Brasil; \\ juliana.gulka@ufsc.br \\ Elaine Rosangela de Oliveira Lucas \\ Doutora; Universidade do Estado de Santa Catarina, Florianópolis, SC, Brasil; \\ lani@udesc.br
}

Resumo: Em um contexto de grande conectividade, um portal de periódicos precisa acompanhar as tendências de presença digital, além de utilizar plataformas e estratégias de forma planejada. Esta pesquisa apresenta uma proposta de análise da presença digital - a partir de um referencial teórico do marketing digital em portais de periódicos. Com o movimento de acesso aberto, o uso de periódicos eletrônicos foi intensificado, de modo que os portais de periódicos também ganharam mais espaço, já que sua implantação propicia questões estratégicas ao contribuir para o aumento da visibilidade e do valor público das instituições, indicando a qualidade da entidade à medida que esta toma para si a responsabilidade pela preservação e disseminação dos periódicos, contribuindo para a expansão da comunicação científica. O marketing digital desponta como a aplicação de estratégias de marketing na internet ou, ainda, em ambiente digital. A proposta apresentada aborda as presenças própria e espontânea, não apresentando formas de análise para a presença digital paga. Como proposta são descritas três etapas: (1) primeira etapa: identificação da presença digital própria; (2) segunda etapa: identificação da presença digital espontânea; e (3) terceira etapa: análise dos dados. A mescla de ferramentas, tipos de metodologias, coletas e softwares apontam para resultados mais amplos das várias faces que as presenças digitais apresentam, já que cada uma possui características peculiares. A proposta apresentada pode ser utilizada para diagnóstico da presença digital de portais de periódicos, apontando melhorias.

Palavras-chave: Presença digital. Portal de periódicos. Marketing digital. Acesso aberto.

\section{Introdução}

A comunicação científica passou por mudanças ao longo dos séculos, da tradição oral ao uso de cartas, culminando na criação de periódicos científicos. Os periódicos são considerados um dos mais importantes canais formais de 


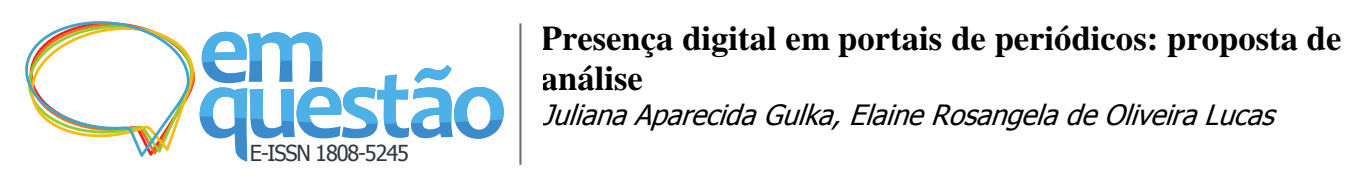

comunicação da ciência, o que garante o reconhecimento de ideias, autores e descobertas, e impulsiona o avanço de pesquisas e comunidades acadêmicas.

E foi com a tecnologia e, principalmente, a internet que o periódico científico rompeu barreiras de tempo e espaço e se tornou online. Com a transição do modelo impresso para o eletrônico, houve a necessidade de se gerir as coleções de periódicos de outra forma, o que ocasionou o surgimento das bases de dados e dos portais de periódicos. Os portais acabam por ter um papel de agrupamento de periódicos institucionais que até então se encontravam dispersos pela rede, além de auxiliar em elementos de gestão de qualidade dessas publicações.

Em um contexto de grande conectividade, um portal de periódicos precisa acompanhar as tendências de presença digital, além de utilizar plataformas e estratégias de forma planejada. O marketing, à medida que auxilia no aproveitamento das oportunidades que o mundo digital oferece, potencializa essas estratégias.

Nesse sentido, esta pesquisa pretende apresentar uma proposta para a análise da presença digital a partir de referencial teórico do marketing digital em portais de periódicos.

\section{Portais de periódicos científicos}

A dinâmica para romper as barreiras de acesso em conjunto com a tecnologia fez surgir um novo local, responsável por reunir os periódicos dispersos na rede: os portais de periódicos. Com o movimento de acesso aberto, o uso de periódicos eletrônicos foi intensificado, de modo que os portais também ganharam mais espaço, à medida que forneciam o apoio a essa forma inovadora de comunicação científica.

Rodrigues e Fachin apontam que

$$
\begin{aligned}
& \text { A organização de periódicos em Arquivos Abertos e Acesso Livre em } \\
& \text { instituições públicas responde ao incentivo das agências } \\
& \text { governamentais, especialmente as vinculadas aos programas de pós- } \\
& \text { graduação (RODRIGUES; FACHIN, 2010, p. 40). }
\end{aligned}
$$

Marra e Weitzel (2015) também comentam que foi justamente o acesso aberto que facilitou as iniciativas de implantação dos portais de periódicos, 


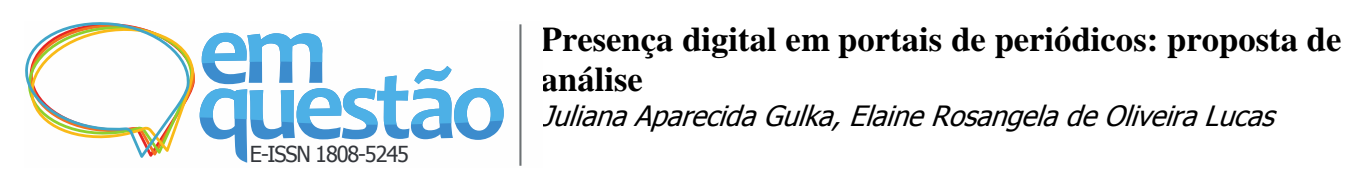

sobretudo em universidades.

Um portal de periódicos dispõe, organiza e recupera periódicos científicos institucionais de forma rápida e segura, aliado à padronização das informações. Salienta-se que os periódicos são institucionais, mas os arquivos que estes publicam provêm de autores de fora da instituição, o que acaba por diferenciar repositórios de portais, além de, como já citado, os portais possuírem revisão por pares em suas revistas. Além disso, "o uso de portais permite a integração, colaboração e personalização baseadas na utilização de recursos das TIC e da Web" (RODRIGUES; FACHIN, 2010, p. 38).

A implantação de um portal de periódicos também propicia questões estratégicas, ao contribuir para: “[...] o aumento da visibilidade e do valor público das instituições", indicando a qualidade da entidade na medida em que esta toma para si a responsabilidade pela preservação e disseminação dos periódicos, contribuindo para a expansão da comunicação científica (RODRIGUES; FACHIN, 2010, p. 38).

Dessa forma, ao ser institucionalizado, um portal passa a contar com as instalações essenciais ao seu bom funcionamento, que permitem que seja mantido em atividade 24 horas do dia, sete dias por semana. Além disso, a responsabilidade institucional fornece mais credibilidade, seja através da identidade visual, do conselho ou das políticas editoriais, seja em relação às competências necessárias para a preservação de dados, padrões, suporte técnico ou treinamentos, já que "o papel da instituição concentra-se nas questões que se referem ao coletivo de todos os periódicos" (GARRIDO; RODRIGUES, 2010, p. 61).

Oliveira (2012) argumenta que profissionais de diversas áreas são demandados para trabalhar com um portal de periódicos. Para o autor, em geral os editores trabalham em conjunto com bibliotecários e analistas de sistemas, evidenciando uma parceria na resolução de problemas e tomadas de decisões.

\section{Marketing digital}

De acordo com Kotler, Kartajaya e Setiawan (2010, p. 31), "para estimular a demanda de produtos, o marketing evoluiu de um nível puramente tático para um 
nível mais estratégico", passando a fazer parte de uma fase completamente centrada em valores, denominada 3.0: “em vez de tratar as pessoas simplesmente como consumidoras, os profissionais de marketing as tratam como seres humanos plenos: com mente, coração e espírito" (KOTLER; KARTAJAYA; SETIAWAN, 2010, p. 4). As mudanças são ainda mais impulsionadas pela globalização e colaboratividade, nas quais as pessoas deixam de ser apenas consumidoras e se tornam também produtoras.

A definição proposta pela American Marketing Association, em sua última versão, aprovada em 2013, também evidencia que o marketing pode impactar em uma escala mais ampla, implicando na sociedade em geral. "Marketing é a atividade, conjunto de instituições e processos para criar, comunicar, entregar e trocar ofertas que tenham valor para os consumidores, clientes, parceiros e sociedade em geral" (AMERICAN MARKETING ASSOCIATION, 2013, tradução nossa).

O marketing digital desponta como a aplicação de estratégias de marketing na internet ou, ainda, em ambiente digital, englobando conceitos, plataformas e estratégias a fim de desenvolver ações no cenário digital emergente. Nesse sentido, Adolpho (2011, p. 66) salienta que "o papel do marketing, agora digital, é aumentar o valor percebido pelo consumidor".

Gabriel relaciona algumas plataformas que são utilizadas para o desenvolvimento de estratégias digitais de marketing:

- Páginas digitais (sites, minisites, hotsites, portais, blogs e perfis);

- E-mail;

- Realidades mistas (realidade aumentada, virtualidade aumentada, realidade virtual);

- Tecnologias mobile (RFID, mobile tagging, SMS/MMS, Bluetooth, aplicativos, mobile TV);

- Plataformas digitais de redes sociais;

- Plataformas digitais de busca (Google, Yahoo, Bing, Wolfram, Alpha, etc.);

- Games e entretenimento digital;

- Tecnologias inteligentes de voz;

- Vídeo/tv digital/vídeo imersivo. (GABRIEL, 2010, p. 107).

Essas plataformas podem ser utilizadas para desenvolver ações combinadas de estratégias digitais, já que atualmente "o papel da empresa na 
economia digital é construir relacionamentos" (ADOLPHO, 2011, p. 216). Essas estratégias, por sua vez, potencializam a presença digital.

\subsection{Presença digital: visibilidade e interação}

Acompanhar o desenvolvimento e a adoção de tecnologias e canais de comunicação pode auxiliar tanto na previsão de novos nichos de atuação quanto na adaptação da organização na utilização desses meios. Corrêa defende que:

\footnotetext{
$\mathrm{Na}$ cena organizacional a realidade digital é inerente ao próprio funcionamento de uma empresa. Não importa o tamanho e seu campo de atuação, o uso de computadores é indispensável. Sistemas integrados de gestão, páginas e portais corporativos na web e intranets são hoje meios de operação, conexão e expressão usuais de uma organização com seus diferentes públicos. (CORRÊA, 2009, p. 163).
}

Para a autora, atualmente a questão central é o processo de comunicação em redes e a construção de relacionamentos, alterando a rotina comunicacional das empresas, equilibrando a relação entre emissores e receptores (CORRÊA, 2009).

A relação entre as organizações, as tecnologias digitais e a comunicação possui como uma questão a ser percebida a adequação à rapidez das inovações digitais, de modo que é exigido flexibilidade e criatividade dos profissionais e da organização, para que haja novos posicionamentos e conhecimentos, visando a “[...] absorção e implementação por parte da organização (delimitada pela estrutura) e dos públicos (motivados pelo protagonismo adquirido)." (CORRÊA, 2009, p. 163)

As mudanças provocadas, sobretudo pela informática, possibilitaram ao marketing a utilização de ferramentas e técnicas que auxiliam no relacionamento com o consumidor. $\mathrm{O}$ estudo das estratégias aplicadas a plataformas digitais “[...] como sites, blogs, sites de busca, sites de relacionamento social, aplicativos e dispositivos é relevante, pois isso impactou e transformou a sociedade, o mercado e os consumidores." (SILVA, 2016, p. 43).

Com a disponibilização da banda larga, a participação do consumidor aumentou, de modo que ele agora atua, escolhe, opina, cria e influencia, fomentando o cenário do marketing contemporâneo (SILVA, 2016). 
Dessa forma, a internet é uma ferramenta e um espaço de marketing digital, na medida em que a organização tem a possibilidade de construir um envolvimento com seu consumidor,

[...] atraindo-o para a participação em seu conteúdo ou mídia em ações como a realização de uploads de vídeos ou fotos, a postagem de comentários, vindo a ser fã da página da marca em sites de relacionamento. (SILVA, 2016, p. 47).

Essa utilização da internet também facilitou a presença digital das pessoas e organizações. No entanto, estar lá simplesmente não garante bons resultados, é preciso que a presença digital esteja alinhada com os objetivos e as metas da instituição, planificadas por meio de estratégias.

De acordo com Corrêa (2009) existem diferentes níveis de posicionamento de uma organização referente à presença digital. É preciso considerar, para isso, os cenários, que podem ser 1.0 ou 2.0. A autora argumenta que no cenário 1.0 há baixa intervenção do receptor à comunicação, bem como baixa personalização do conteúdo e um predomínio do emissor no controle. Exemplos desse cenário são os sites, intranets, e-mail, portais corporativos e boletins digitais. O cenário 2.0, por sua vez, revela a tendência à participação e à geração de conteúdos pelo próprio usuário, de modo a se inspirar na web 2.0 para deslocar do emissor a centralização das mensagens emitidas. De acordo com a autora, as plataformas e ferramentas mais utilizadas nesse cenário são, por exemplo, os blogs, microblogs, RSS, widgets, mídias sociais, locais de compartilhamentos de vídeos e fotos, wikis e podcasts.

Entretanto, uma organização não precisa, necessariamente, se definir como integrante de um dos cenários, pois tanto o 1.0 quanto o 2.0 "são cenários concomitantes e interdependentes", devendo então a instituição definir em quais mídias quer estar presente digitalmente (CORRÊA, 2009, p. 165).

Silva (2016, p. 48) defende que "a presença digital origina os pontos de contato entre o público-alvo e a marca no ambiente digital, constituindo o estabelecimento das marcas no meio digital”. Para Strutzel,

Presença Digital, Marketing Digital, Marketing Online são algumas das denominações mais comuns para as ações de comunicação no ambiente da internet e, seja qual for a denominação preferida, este assunto não é um mero modismo ou uma febre passageira. (STRUTZEL, 2015b, p. xiii). 
De forma simplificada, a presença digital é a "existência de algo (seres humanos, marcas, empresas, coisas, etc.) no ambiente digital" (GABRIEL, 2010, p. 249) ou, ainda, a representação da “[...] existência de uma entidade nas mídias digitais e sociais" (STRUTZEL, 2015b, p. 87). Entretanto, de acordo com Strutzel (2015a), apesar da utilização do termo presença digital ter se tornado mais comum, seu significado ainda não foi bem assimilado, sobretudo pelo mercado, de forma que sua compreensão ainda se dá de forma superficial. Isso pode ser percebido na utilização do termo na literatura científica, que é ainda bastante tímida, tendo este sido citado de forma mais frequente em blogs que tratam dos temas digitais contemporâneos.

Estar presente digitalmente significa criar pontos de contato com o público, por isso o conteúdo distribuído em diversos ambientes digitais pode parecer simples, mas o seu funcionamento de fato é fruto de técnicas e metodologias previamente implantadas. São esses conteúdos que fazem a representação da organização no ambiente online, e muitas vezes não ter presença digital significa, para o público-alvo, não existir também no mundo real. A título de exemplo, tem-se o site de uma organização, que "é um ponto de presença digital, a qual se origina da existência de conteúdo digital” (SILVA, 2016, p. 49).

Strutzel (2015a, doc. não paginado) defende que "a presença digital verdadeira tem que ser orientada por objetivos e gerar oportunidades reais de negócios para a entidade que a coloca em prática”. Ou seja, utilizar os canais digitais para atingir o objetivo da instituição é um fator crucial para o retorno dessa presença.

É possível ainda refletir sobre isso tendo como base a afirmação de Adolpho (2011, p. 262), que enfatiza: "a melhor maneira de encontrar o seu consumidor é ser encontrado por ele", que salienta a necessidade, no contexto contemporâneo, de ser encontrado em meio a uma quantidade enorme de organizações nos diversos segmentos, que pulverizam na sociedade diversas formas de se propagar.

Gabriel (2010) e Strutzel (2015b) utilizam terminologias semelhantes para identificar três grupos de presença digital, que devem ser equilibrados no 
momento de definir o percurso para planejar e investir no ambiente online. No Quadro 1 é possível visualizar a categorização feita pelos autores.

Quadro 1 - Tipos de presença digital.

\begin{tabular}{|l|l|l|l|}
\hline $\begin{array}{c}\text { GABRIEL } \\
(\mathbf{2 0 1 0})\end{array}$ & $\begin{array}{l}\text { STRUTZEL } \\
(\mathbf{2 0 1 5 b )}\end{array}$ & \multicolumn{1}{|c|}{ DEFINIÇÃO } & \multicolumn{1}{c|}{ EXEMPLOS } \\
\hline $\begin{array}{l}\text { Presença } \\
\text { Própria }\end{array}$ & $\begin{array}{l}\text { Mídia } \\
\text { Própria }\end{array}$ & $\begin{array}{l}\text { Promovida pela própria } \\
\text { organização, que tem } \\
\text { autonomia no gerenciamento } \\
\text { dos canais. }\end{array}$ & Website, blog, mídias sociais. \\
\hline $\begin{array}{l}\text { Presença } \\
\text { Gratuita }\end{array}$ & $\begin{array}{l}\text { Mídia } \\
\text { Espontânea }\end{array}$ & $\begin{array}{l}\text { São conteúdos publicados por } \\
\text { terceiros ou gerados por meio } \\
\text { de ranqueamentos. }\end{array}$ & $\begin{array}{l}\text { Resultados no Google, } \\
\text { conteúdos gerados em mídias } \\
\text { sociais, reclamações, } \\
\text { comentários positivos ou } \\
\text { negativos, check-ins. }\end{array}$ \\
\hline $\begin{array}{l}\text { Presença } \\
\text { Paga }\end{array}$ & Mídia Paga & $\begin{array}{l}\text { Conteúdos e canais } \\
\text { comprados ou pagos pela } \\
\text { organização, para gerar } \\
\text { exposição ou audiência } \\
\text { mediante a monetização. }\end{array}$ & $\begin{array}{l}\text { Links patrocinados, publicações } \\
\text { promovidas (Facebook), } \\
\text { anúncios, banners. }\end{array}$ \\
\hline
\end{tabular}

Fonte: Elaborado pelas autoras com base em Gabriel (2010) e Strutzel (2015b).

É possível notar que os autores atribuem termos diferentes para especificar a presença gratuita ou espontânea, mas que as presenças apresentadas são, dentro de cada grupo, essencialmente iguais. Para fins de unicidade, este trabalho utilizará os termos "presença digital própria", "presença digital espontânea" e "presença digital paga", quando se referir à categorização de presenças digitais.

Os exemplos apontados na quarta coluna do Quadro 1 são apenas uma parcela de atuação de cada categoria, mas salientam uma gama de possibilidades de ações. Silva define a presença digital própria como sendo os

[...] conteúdos digitais da empresa, desenvolvidos e mantidos pela própria organização, tais como sites, minisites, hotsites, portais, blogs, páginas em redes sociais as quais podem ser exemplificadas por perfis e canais no LinkedIn, Twitter, YouTube, Google Profile e outros. [...] Também se incluem na presença própria, o envio de e-mail marketing e newsletters; games, conteúdo de entretenimento e aplicativos móveis, desenvolvidos com a marca da organização. (SILVA, 2016, p. 49).

Essa presença se refere a tudo aquilo que a instituição mantém de forma intencional (seja planejada ou não), ou seja, de forma consciente. 


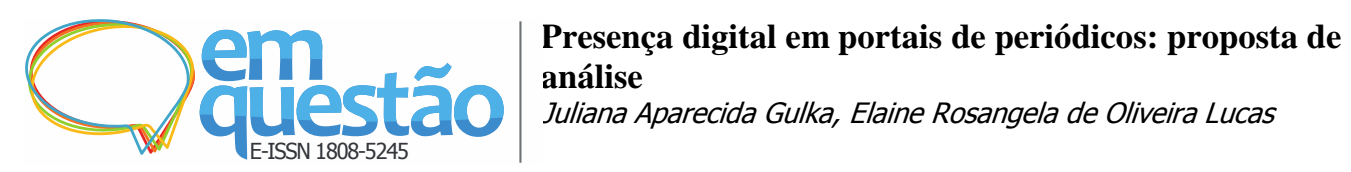

A presença digital espontânea, por sua vez,

[...] é aquela em que os ativos digitais com a marca da empresa são gerados e ganhos de modo orgânico na internet; é algo como, por exemplo, estar incluído nos resultados de pesquisa orgânica em sites de busca, bem como aparecer nas conversas nas redes sociais. (SILVA, 2016, p. 49).

Mesmo que a marca ou organização não possua uma presença digital própria, esta poderá ter a espontânea, já que esses conteúdos são gerados por terceiros, de forma que qualquer usuário ou consumidor pode fazer a marca estar presente na internet.

A presença digital paga “[...] é aquela em que os ativos digitais com a marca da empresa são comprados, como, por exemplo, anúncios em sites, links patrocinados e outros" (SILVA, 2016, p. 49).

A combinação das três categorias pode resultar em um bom retorno para a organização, mas apesar de parecer simples, a presença digital exige estratégias que levam em conta aspectos como marketing, comunicação e informática, por exemplo, de modo que é o seu bom uso que potencializa os pontos de contato com o público-alvo nos três tipos de presença apresentados anteriormente, sendo a espontânea a mais difícil de otimizar.

Entender a tecnologia envolvida é uma das premissas básicas para explorar de forma satisfatória o ambiente digital. Gabriel (2010) ressalta a combinação de três elementos para o desenvolvimento de uma boa estratégia de presença digital: marketing, tecnologia e design. Essa combinação, se bem aplicada, tem o objetivo de propiciar o posicionamento e os objetivos ideais para a organização, além de fornecer a estrutura para a sua implantação e a oferta de conteúdo ideal para o público-alvo. Além disso,

\footnotetext{
A multiplicidade de tecnologias e plataformas digitais disponibiliza um campo muito produtivo para vários tipos de ações de marketing, possibilita a mensuração e a sincronicidade, que são grandes vantagens se comparadas ao ambiente material tangível. (SILVA, 2016, p. 47-48).
}

Mas a utilização dessas plataformas não segue nenhuma receita pronta, pois tudo depende de cada marca, cada organização. Strutzel (2015a, doc. não paginado) esclarece que "ainda que existam soluções prontas e empacotadas disponíveis no mercado, a presença digital é uma ação totalmente personalizada, 


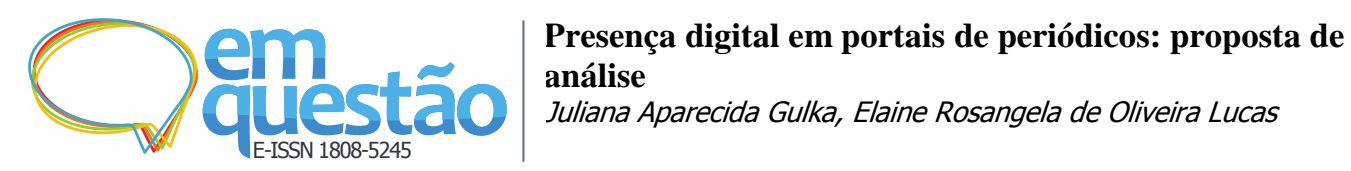

de acordo com o DNA e a personalidade de cada empresa ou instituição". Dessa forma, a presença digital segue o posicionamento e os objetivos estabelecidos pela organização.

Nessa perspectiva, as estratégias das instituições podem ser diferentes umas das outras, e seus elementos podem ser mais simples ou mais complexos, dependendo do caso. Para se fazer marketing digital, o primeiro passo é entender as plataformas, depois "as estratégias digitais podem relacionar vários tipos de tecnologia, [...] uma estratégia de presença digital pode ser a combinação de site, blog e Facebook" (SILVA, 2016, p. 48).

Para Gabriel (2015, doc. não paginado), o desafio está em articular as plataformas escolhidas, a fim de se proporcionar uma boa experiência ao usuário, mas para isso "[...] é necessário planejamento de presença digital, conhecimento de uso das plataformas escolhidas, monitoramento e métrica, e coordenação de tudo isso com o mundo off-line". A autora ainda afirma que as instituições que resistirem às estratégias digitais não vão sobreviver, pois atualmente tudo está dependente do digital, da tecnologia.

Corrêa (2009, p. 165-166) acrescenta que “[...] os parâmetros de mensuração do retorno adentram por itens como qualificação do tráfego, geração de boca-a-boca digital (viral), reputação e imagem digitais, por exemplo", e essas atividades e tendências exigem que a organização, por meio de seus profissionais e das instituições que os formam, desenvolvam novas competências, a fim de atender aos aspectos da comunicação digital.

No que tange à presença digital espontânea, um dos fatores de influência são os resultados que os mecanismos de busca apresentam e seu ranqueamento. Silva (2016, p. 50) identifica que os resultados apresentados pelos buscadores são pertencentes a duas categorias: "[...] as que se originam do processo natural de seleção dos sites, o que é definido como busca orgânica, e os resultados de busca paga". A busca orgânica, de acordo com a autora, apresenta resultados que são captados pelos buscadores por meio de análise que considera a relevância do site e das palavras-chave de busca.

De acordo com Strutzel (2015a), atualmente, falar de buscadores é praticamente um sinônimo de falar do Google, o que não deve ser menosprezado, 


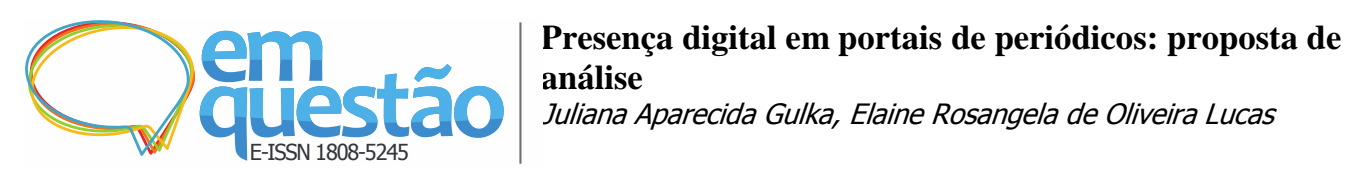

já que em âmbito nacional isso significa cerca de $92 \%$ das pesquisas realizadas. Para o autor, os sites de busca alcançaram uma posição de destaque, de modo que estes inclusive são um dos eixos do marketing digital e "[...] representa um dos principais caminhos para uma presença digital consistente" (STRUTZEL, 2015b, p. 29). Alinhar ações que visem a otimização deste com os demais canais digitais, como a presença digital própria, pode proporcionar resultados mais efetivos.

Outro fato a ser considerado ao se tratar de presença digital são as tendências que abrem caminhos para possibilidades diversas de atuação. Corrêa destaca que

\footnotetext{
Hoje, a grande tendência da Comunicação Corporativa que se expressa no mundo das redes digitais é criar presença em novos territórios de relacionamento com os públicos em redes sociais, em dispositivos móveis, em experiências de cloud computing, entre as muitas possibilidades. (CORRÊA, 2009, p. 165, grifo do autor)
}

Essas tendências não precisam necessariamente ser todas implantadas pela organização, mas seu conhecimento é necessário, no mínimo, para avaliação do que se adéqua às propostas e objetivos da empresa, sobretudo se for considerada a convergência digital.

Strutzel (2015b, p. 13) aponta que o termo convergência digital é relativamente novo, já que começou a aparecer há cerca de dez anos e pode ser definido como “[...] a concentração de funções em um único dispositivo pessoal e intransferível", como os smartphones e tablets, por exemplo, equipamentos muito presentes na sociedade contemporânea. De acordo com o autor, a convergência precisa ser compreendida e considerada no momento do planejamento da presença digital e também na sua implantação e gestão.

A gestão de presença digital, por sua vez, visa estabelecer uma conexão mais forte com os interagentes na infinidade de canais que a web proporciona. $\mathrm{O}$ planejamento solidifica a gestão dessa presença, sobretudo se levar em consideração alguns pilares, apontados no Quadro 2. 
Quadro 2 - Pilares da presença digital.

\begin{tabular}{|c|ll|}
\hline AUTORES & \multicolumn{2}{|c|}{ PILARES } \\
\hline Strutzel (2013) & 1. & Posicionamento \\
Wolcow (2015) & 2. & Conteúdo \\
Leite (2016) & 3. & Relacionamento \\
& 4. & Monitoramento \\
\hline & 1. & Planejamento \\
Back (2012) & 2. & Conteúdo \\
& 3. & Relacionamento \\
& 4. & Monitoramento \\
\hline & 1. & Identidade Digital \\
Coscelli (2014) & 2. & Conteúdo \\
& 3. & Tráfego \\
& 4. & Mensuração \\
\hline
\end{tabular}

Fonte: Elaborado pelas autoras.

É possível notar que todos os autores elencados no quadro acima apontam para quatro pilares da presença digital, que, por sua vez, apresentam semelhanças e diferenças.

O posicionamento, elencado por Leite (2016), Strutzel (2013) e Wolcow (2015) e, pode ser entendido como a forma que a organização se coloca, seria a criação de um perfil, a fim de delinear como a organização quer ser percebida no ambiente online. Esse pilar também tem o mesmo significado para Coscelli (2014), que o nomeia identidade digital. O primeiro pilar defendido por Back (2012), no entanto, é o planejamento. De acordo com a autora, este é o pontochave e fornece a base para a implantação dos demais pilares.

O segundo pilar da presença digital, apontado por todos os autores citados no Quadro 2, é o conteúdo. A produção de conteúdo auxilia a organização a se tornar relevante para o usuário ou consumidor, fornecendo autoridade e integrando as ações, inclusive influenciando nos resultados de buscadores.

Relacionamento é o terceiro pilar, apontado por quatro dos cinco autores. A autoridade de quem publica pode propiciar a geração de relacionamentos, que por sua vez facilitam o engajamento dos usuários com a organização, a partir dos canais digitais. Esse pilar, à medida que aproxima a instituição ou marca do público, fomenta a retenção de clientes. Coscelli (2014) aponta como quarto pilar o tráfego. Para o autor, significa atrair o maior número possível de pessoas, sendo que ele não cita o relacionamento para atingir esse fim, apenas salienta que os canais digitais propiciam atingir esse pilar com menor custo, sendo mais acessível. 
Por fim, o quarto e último pilar é apontado pelos autores como monitoramento ou mensuração, que possuem significados semelhantes. Significa, basicamente, acompanhar os resultados que os canais digitais propiciam, visando o desenvolvimento de prospecções e a tomada de decisão.

Considera-se que qualquer gestão parte do planejamento, e que este é necessário para que haja o posicionamento ou o delineamento da identidade digital, de forma alinhada com os objetivos e a missão da instituição. É a partir desses elementos que se tem o conteúdo e o relacionamento, itens que auxiliarão na geração de tráfego para os canais digitais.

Strutzel (2015b) apresenta também quatro fases voltadas para um modelo satisfatório de presença digital.

A primeira fase apontada pelo autor é a de existência. Está relacionada à necessidade da organização de adotar a cultura da internet e quebrar paradigmas, fazendo-se presente no ambiente online de forma relevante e não estática, exercendo uma presença digital atuante. A existência é o ponto-chave junto ao planejamento.

A segunda fase, de acordo com Strutzel (2015b), é a atração. Está relacionada aos pontos de contato estabelecidos e à produção de conteúdo, que precisa ter frequência, relevância, equilíbrio e qualidade.

A terceira fase trata do relacionamento, item também presente no modelo apresentado no Quadro 2. Trata-se do acompanhamento constante das ações realizadas junto ao público, percepção de feedback e respostas às interações feitas.

A quarte fase, por fim, é a de engajamento. De acordo com Strutzel (2015b), esse é o nível máximo de relacionamento do público com a instituição ou marca, e é um conceito condicional que está mais relacionado às mídias sociais.

A escolha do tipo de plataforma para estabelecer a presença digital da organização depende de seu foco, seus objetivos e sua missão. De acordo com Gabriel (2010), o modo mais simples para estabelecer uma presença digital pode ser por meio de blogs ou mídias sociais, que não exigem conhecimentos profundos de tecnologia e design. A autora compara as ações de presença digital com a de um pescador: "estar onde os peixes estão", por isso é necessário 
determinar onde se quer atuar, visando estabelecer pontos de contato com o público (GABRIEL, 2010, p. 253).

É necessário ressaltar que a web e as tecnologias digitais são dinâmicas e trazem possibilidades de atuação, mas ao mesmo tempo pulverizam informações de forma vertiginosa. O ambiente digital, se considerado em suas diversas dimensões, pode sim propiciar, a partir de um planejamento, a existência de uma presença digital consolidada e alinhada aos princípios da instituição. A familiaridade com os meios digitais é crucial nessa atuação, servindo para a seleção criteriosa das mídias, estratégias e tomadas de decisão.

\section{Proposta para análise de presença digital de portais de periódicos}

Os portais de periódicos são, essencialmente, locais na web que reúnem uma gama de publicações institucionais. Além disso, proporcionam aos periódicos ali hospedados a infraestrutura necessária para o desempenho de suas funções editoriais, dando suporte técnico e operacional às atividades. Institucionalmente, preocupam-se com a qualidade dos periódicos científicos, buscando desenvolver diretrizes e políticas editoriais que auxiliem na melhoria das publicações, objetivando a visibilidade científica no que tange a indexadores e indicadores.

Em âmbito digital, o portal de periódicos é o ambiente que pode ser considerado ponto de partida para a comunicação e divulgação científica, pois por meio de seu site oferece uma presença digital com certa autoridade. Porém, na sociedade contemporânea, parece não ser suficiente essa presença, devendo-se considerar outras possibilidades.

É nesse sentido que se resgatam aqui alguns conceitos, a fim de contextualizar a presença digital, relacioná-la com os portais de periódicos e, posteriormente, apresentar a proposta pensada para sua análise.

A presença digital, portanto, se subdivide em três categorias: Presença própria, que considera os locais onde a instituição está de forma consciente na internet; Presença espontânea, locais onde a instituição está, mas fomentados por terceiros (inclusive buscadores); e Presença paga, que se refere à presença feita por meio de anúncios e publicidade (GABRIEL, 2010; STRUTZEL, 2015b). O 


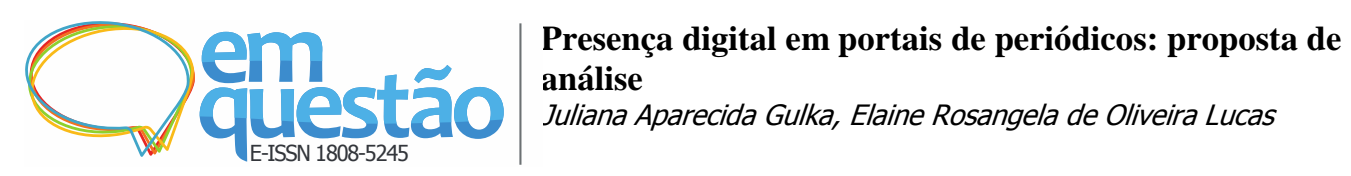

fato, porém, dos portais de periódicos responderem a uma demanda de publicações em acesso aberto pode fomentar a utilização dos canais digitais para promover a presença digital.

A proposta aqui apresentada pode assegurar a aplicação dos pilares da presença digital, tanto para seu início, na medida em que fornece um diagnóstico, quanto para sua constante mensuração. A proposta se baseia fundamentalmente na coleta de dados, que são as principais etapas para assegurar que o cruzamento de dados seja feito de forma a garantir a confiabilidade das informações. Apresentase, portanto, duas etapas referentes à coleta de dados, sendo a primeira a presença digital própria e a segunda a presença digital espontânea.

A primeira etapa visa identificar em quais locais o portal de periódicos mantém uma presença digital própria, de forma consciente e intencional. Essa verificação visa elencar em quais outros locais, além do site, que é o ponto de partida, o portal está. Sua identificação se dá a partir da exploração do site em busca de ícones e hyperlinks que indiquem o direcionamento para outras presenças digitais próprias.

A identificação da presença digital própria não leva em conta os periódicos hospedados pelo portal, pois os mesmos não são considerados presenças próprias do portal em si, seriam outro ponto de partida para análises individuais de cada revista.

Os dados coletados na exploração do site institucional devem ser organizados em planilha própria. Para cada presença digital própria identificada a partir do site, registram-se suas informações básicas, como nome, URL, a qual categoria pertence (mídias sociais, site, entre outros), etc. Essas informações podem ser compostas de mais ou menos itens, de acordo com o objetivo da pesquisa. Essencialmente, elas devem ser capazes de auxiliar na posterior análise das presenças identificadas.

A segunda etapa da proposta corresponde à identificação da presença digital espontânea, que por sua vez é realizada a partir dos dados coletados na primeira etapa.

A identificação da presença digital espontânea é realizada utilizando os URLs de cada presença digital própria coletada anteriormente. Para cada presença 
digital própria é verificada sua respectiva presença digital espontânea. Dessa forma, os respectivos URLs devem ser submetidas a um software ou ferramenta que seja capaz de retornar resultados automaticamente, como, por exemplo, backlinks, dados que dizem respeito ao alcance e à visibilidade da página na web. O registro dos resultados fica a cargo de cada software utilizado e da possibilidade de sua versão ser gratuita ou paga, o que os diferencia em relação aos recursos disponíveis para salvar os materiais, que podem ser por meio de planilhas, arquivos PDF, print screen, etc.

Um ponto a destacar é que as duas primeiras etapas da proposta devem ser realizadas com o menor intervalo possível entre elas. Isso se justifica em virtude do caráter efêmero da internet, que pode influenciar nos resultados obtidos e causar interferências na pesquisa.

Com base nos dados resultantes das duas etapas de coleta de dados, procede-se à sua apresentação e análise, que podem ocorrer de forma separada ou conjunta. O que é necessário verificar nessa etapa é o retorno que a presença digital espontânea fornece em relação a cada canal utilizado como presença digital própria pelo portal. Ao cruzar esses dados é possível inferir se existe alguma relação com outros elementos identificados na presença digital própria, como, por exemplo, seu nome ou identificação no URL, bem como relacionar os dados com outros elementos resultantes de pesquisa documental, como, por exemplo, relatórios institucionais.

Outro elemento que pode ser considerado é a análise de hyperlinks, que considera técnicas quantitativas para reconhecer que a quantidade de links significa algum tipo de relevância ao site citado. Dependendo do software que foi utilizado para a coleta de dados, seus resultados podem também indicar outras possibilidades de análises mais profundas, como a Teoria de Redes Sociais. Essa teoria aborda as conexões entre os sites, revelando suas dinâmicas e representando-as por meio de grafos (FRAGOSO; RECUERO; AMARAL, 2011).

Por fim, a quarta etapa da proposta sugere que, a partir dos resultados obtidos e da análise realizada, sejam apontadas possibilidades de melhorias, que podem ser baseadas nos pilares de gestão: planejamento, posicionamento ou identidade digital, conteúdo, relacionamento, tráfego, mensuração ou 
monitoramento (BACK, 2012, COSCELLI, 2014; LEITE, 2016; STRUTZEL, 2013; WOLCOW, 2015).

A figura abaixo apresenta as fases da proposta:

Figura 1 - Proposta para análise de presença digital de portais de periódicos.

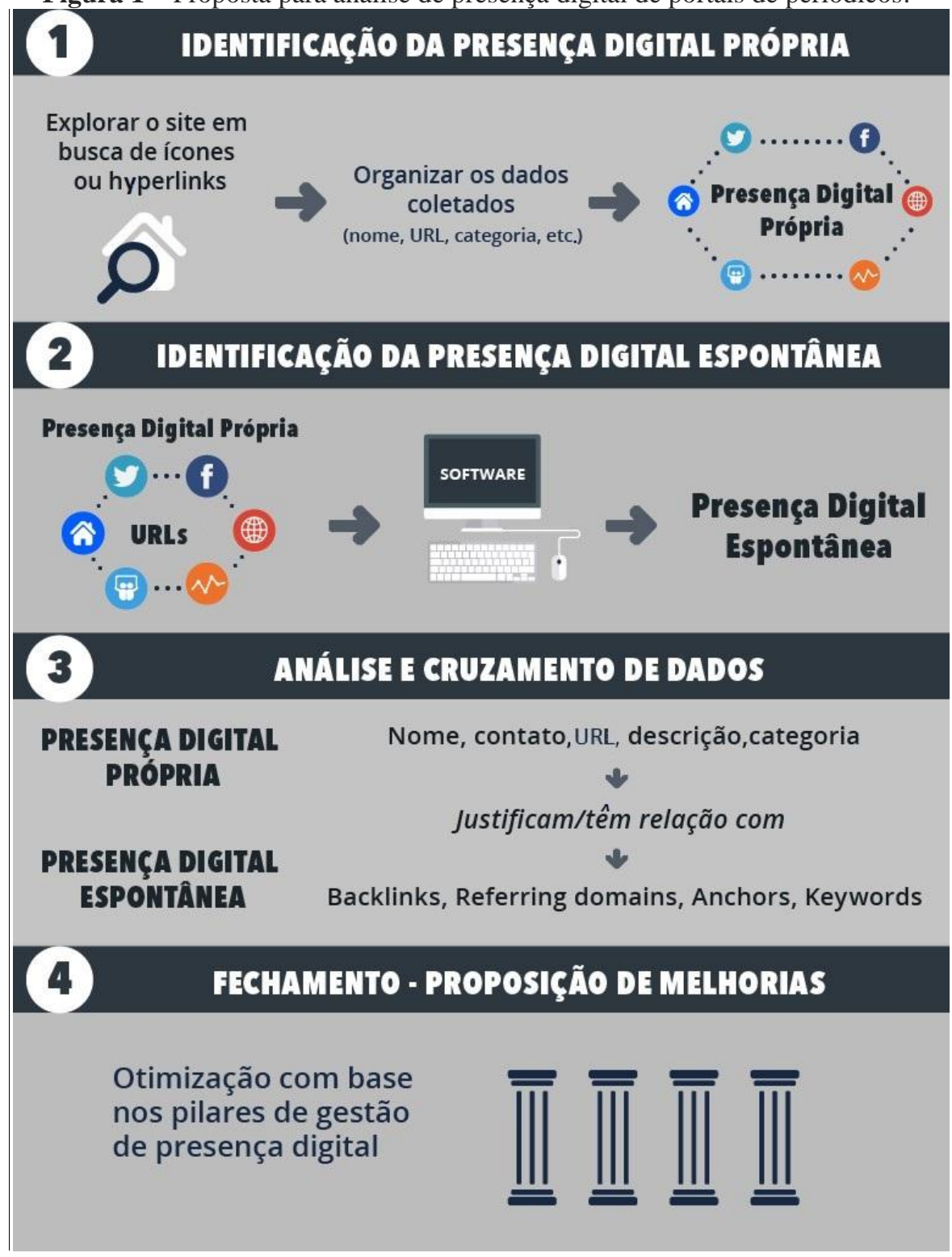

Fonte: Elaborado pelas autoras.

\section{Considerações finais}

Este estudo não se esgota em si mesmo, visto que há ainda outros aspectos que podem ser apreciados com o intuito de gerar resultados mais completos que auxiliem na tomada de decisão. Análises segmentadas, por categoria de mídia 


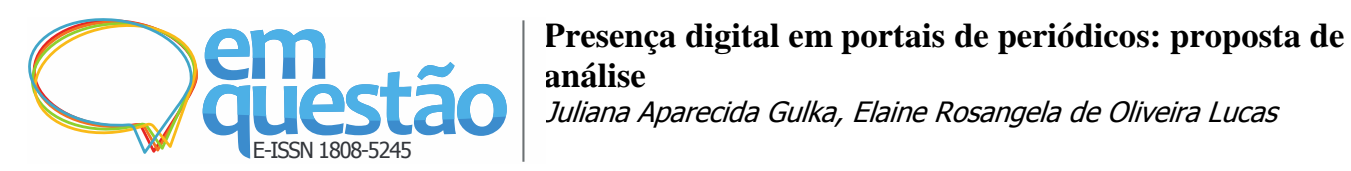

social, por exemplo, parecem ser necessárias para melhor compreensão de seus fatores, de modo a complementar os resultados apresentados nesta pesquisa. Destaca-se, nesse viés, o estudo de Vicente (2015), que apresenta uma sugestão metodológica para análise de redes sociais na internet, com foco na divulgação científica, utilizando a netnografia.

A mescla de ferramentas, tipos de metodologias, coletas e softwares aponta para resultados mais amplos das várias faces que as presenças digitais apresentam, já que cada uma possui características peculiares. Como exemplo tem-se, além da proposta com foco na divulgação científica citada anteriormente, a análise de conteúdo, estudos netnográficos e estudos de usabilidade, que tendem a se complementar em diferentes segmentos.

Por fim, a pesquisa culminou na apresentação de uma proposta para análise da presença digital de portais de periódicos, modelo que pode ser utilizado para aplicação em outras instituições, com vias a realizar um diagnóstico da situação atual e propor as melhorias que forem necessárias.

A Ciência da Informação possui aspectos interdisciplinares que contemplam o trabalho realizado no âmbito do marketing digital, que alia conceitos de tecnologia, internet, Administração, etc. O Bibliotecário, enquanto profissional da informação, tem a necessidade de se ajustar às novas demandas de trabalho que surgem por causa dos ambientes digitais. Dessa forma, possui condições de atuar também na coleta e análise de dados referentes à presença digital de portais de periódicos, desempenhando papéis em planejamentos estratégicos e na tomada de decisões.

Estar presente digitalmente parece ser um caminho com direção única (para frente), sobretudo para os periódicos científicos e, consequentemente, para os portais de periódicos. A gestão da presença digital de um portal de periódicos vai de encontro aos princípios do acesso aberto, na medida em que favorece a disseminação das publicações, garantindo visibilidade e acessibilidade à informação científica, fornecendo credibilidade, pois estão ligadas a uma instituição acadêmica reconhecida pela sociedade.

Concluindo, pode-se afirmar que a validade de uma pesquisa está atrelada ao seu universo e às opções metodológicas escolhidas, o que significa que não é 
possível fazer generalizações a partir dos resultados deste estudo. A ferramenta e os recortes impõem limitações, mas se apresentam como importantes para as análises específicas. O modelo de análise proposto, no entanto, se aplica ao estudo de diferentes aspectos da presença digital, de modo que sua adaptação a diferentes realidades depende da introdução de outras variáveis que possam atuar sobre outras possibilidades de interações.

\section{Referências}

ADOLPHO, Conrado. Os 8Ps do marketing digital. São Paulo: Novatec, 2011.

AMERICAN MARKETING ASSOCIATION. Definition of Marketing. 2013.

Disponível em: <https://www.ama.org/aboutama/pages/definition-ofmarketing.aspx >. Acesso em: 31 maio 2015.

BACK, Caroline. Os 4 pilares do marketing digital.2012. Disponível em: <http://www.ageone.com.br/blog/os-4-pilares-do-marketing-digital/>. Acesso em: 30 dez. 2016.

CORRÊA, Elizabeth Saad. A comunicação digital nas organizações: tendências e transformações. Organicom, São Paulo, v. 6, n. 10/11, p. 162-167, 2009.

COSCELLI, José Geraldo de Barros. Os quatro pilares para ter uma boa presença on-line. [S.1.], 2014. Disponível em:

$<$ http://corporate.canaltech.com.br/dica/marketing/Os-quatro-pilares-para-teruma-boa-presenca-on-line/>. Acesso em: 19 maio 2016.

FRAGOSO, Suely; RECUERO, Raquel; AMARAL, Adriana. Métodos de pesquisa para internet. Porto Alegre: Sulina, 2011.

GABRIEL, Martha. Marketing na era digital: conceitos, plataformas e estratégias. São Paulo: Novatec, 2010.

GABRIEL, Martha. O impacto da internet nos negócios. 2015. Disponível em: <http://www.adflip.com.br/2015/06/08/o-impacto-da-internet-nos-negocios/>. Acesso em: 19 maio 2016.

GARRIDO, Isadora dos Santos; RODRIGUES, Rosangela Schwarz. Portais de periódicos científicos online: organização institucional das publicações.

Perspectivas em Ciência da Informação, Belo Horizonte, v. 15, n. 2, p. 56-72, maio/ago. 2010. Disponível em:

$<$ http://portaldeperiodicos.eci.ufmg.br/index.php/pci/article/view/943>. Acesso em: 10 set. 2015 . 
KOTLER, P.; KARTAJAYA, H.; SETIAWAN, I. Marketing 3.0: as forças que estão definindo o novo marketing centrado no ser humano. Rio de Janeiro: Elsevier, 2010.

LEITE, Fábio Furtado. Presença Digital: uma estratégia de negócios necessária. [S.1.], 2016. Disponível em: 〈http://www.furtadoleite.com.br/presenca digital/>. Acesso em: 19 maio 2016.

MARRA, Patrícia; WEITZEL, Simone. Portais de periódicos de acesso aberto nas universidades brasileiras: a utilização do Open Journal Systems. In: ENCONTRO NACIONAL DE PESQUISA EM CIÊNCIA DA INFORMAÇÃO, 16., 2015, João Pessoa. Anais... João Pessoa: UFPB, 2015.

OLIVEIRA, Alexandre P. O sistema das profissões: o trabalho nos Portais de Periódicos. 2012. Artigo apresentado durante o Mestrado em Ciência da Informação do Programa de Pós-Graduação em Ciência da Informação da Universidade Federal de Santa Catarina.

RODRIGUES, Rosângela; FACHIN, Gleisy. Portal de periódicos científicos: um trabalho multidisciplinar. TransInformação, Campinas, v. 22, n. 1, p. 33-45, jan./abr. 2010. Disponível em: <http://periodicos.puccampinas.edu.br/seer/index.php/transinfo/article/view/483>. Acesso em: 10 set. 2015.

SILVA, Vanessa Bolico da. Marketing digital como ferramenta estratégica e as oportunidades nas redes sociais. E3: Revista de Economia, Empresas e Empreendedores, Souto (Portugal), v. 2, n. 1, p. 25-62, 2016.

STRUTZEL, Tercio. Como a Presença Digital impacta o seu negócio? 29 jan. 2015a. Disponível em: <http://www.terciostrutzel.com.br/como-a-presencadigital-impacta-o-seu-negocio/>. Acesso em: 26 jun. 2015.

STRUTZEL, Tercio. Os 4 pilares da presença digital. [S.1.], 2013. Disponível em: <http://www.administradores.com.br/artigos/marketing/os-4-pilares-dapresenca-digital/73194/>. Acesso em: 15 maio 2016.

STRUTZEL, Tercio. Presença Digital. Rio de Janeiro: Alta Books, 2015 b.

VICENTE, Natalí Ilza. O uso do Twitter e Facebook para divulgação científica: um estudo netnográfico em perfis de bibliotecas universitárias federais do sul do Brasil. 2015. 184 f. Dissertação (Mestrado) - Universidade do Estado de Santa Catarina, Florianópolis, 2015.

WOLCOW, Vitor. Como construir uma presença digital eficiente para o seu negócio. Belo Horizonte, 2015. 


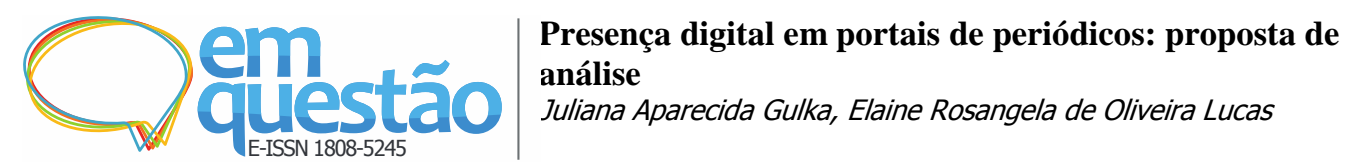

\title{
Digital Presence in Portals for Journals: Analysis Proposal
}

\begin{abstract}
This research presents an analysis proposal of digital presence - from a theoretical reference of digital marketing - in portals for journals. With the open access movement, the use of electronic journals was intensified in such a manner, that portals for journals also gained more space since its deployment provides strategic issues when contributing to an increased visibility and the public value of the institutions, indicating the quality of the entity, as the latter takes on the responsibility for the preservation and dissemination of the journals, thus contributing to the expansion of scientific communication. Digital marketing has emerged as the application of marketing strategies on the internet or even in the digital environment. The presented proposal tackles the own and the spontaneous presence, not presenting any forms of analysis for the paid digital presence. The proposal is divided in three stages: (1) first stage: identification of the "own digital presence"; (2) second stage: identification of the "spontaneous digital presence"; and (3) third stage: analysis of the data. The mixture of tools, types of methodologies, collections and software point to broader results of the various faces of digital presence, since each has unique characteristics. The methodology presented can be used for diagnosis of the digital presence of portals for journals, pointing out improvements.
\end{abstract}

Keywords: Digital presence. Portal for journals. Digital marketing. Open access.

Recebido em: 19/09/2016

Aceito em: 08/11/2016 